in which the subtle, thoughtful, and often equivocal nature of people's views might be allowed to emerge. Rather than seeing attitudes as enduring, homogenous, and as hypostatised internal mental states, it may be more productive and realistic to acknowledge that people construct and express 'attitudes' for particular purposes, in different argumentative contexts, and with differing effects. In the terms of Billig's (1987, p. 225) rhetorical approach, attitudes represent "unfinished business in the continual controversies of social life". The analysis of the structure of argumentation may shed light upon what are often the competing and contradictory results of survey research.

In the second of the two articles, Hall et al misrepresent the study by Segal et al (1980) whom they suggest "found that the mentally ill may seem most socially integrated in neighbourhoods with little social cohesion, and that there was more resistance to their placement in residential as opposed to commercial areas" (Hall et al, p. 106). In fact, Segal et al (1980) do not find this at all. Hall and colleagues appear to be quoting that paper's review of previous research, thus; "Trute and Segal (1976) . . . found the highest levels of social integration among residents of sheltered-care facilities that were located in neighbourhoods with little social cohesion" and "... Piasecki (1975) found that more resistance was encountered in residentially, as opposed to commercially, zoned areas" (Segal et al, 1980, p. 346). But Segal and colleagues go on immediately to say of such studies that "These are simple, unidimensional descriptions with limited practical utility ..." (ibid).

In fact, Segal et al (1980) suggest that what they called the "liberal, non-traditional neighbourhood" may be the "accepting community that researchers have sought" (pp. 352-353). This kind of community is characterised by its liberality, departure from convention, high rate of criminal activity, and other factors, but this should not necessarily be taken to indicate a lack of 'social cohesion'.

BıllıG, M. (1987) Arguing and Thinking: A Rhetorical Approach to Social Psychology. Cambridge: Cambridge University Press.

Gilbert, G. N. \& MUlkay, M. (1984) Opening Pandora's Box: A Sociological Analysis of Scientists' Discourse. Cambridge: Cambridge University Press.

POTTER, J. \& WeTHERELl, M. (1987) Discourse and Social Psychology: Beyond Attitudes and Behaviour. London: Sage.

Segal, S. P., BAumohl. J. \& MAYles, E. W. (1980) Neighborhood types and community reaction to the mentally ill: a paradox of intensity. Journal of Health and Social Behavior, 21, 345-359.

Department of Psychiatry

David SOUTHGate

Barnet General Hospital

Barnet, Hertfordshire EN5 3DJ

\section{An Eysenck for the 1990s?}

SIR: Dr Andrews (Journal, April 1993, 447-451) states that "polemics distract from the essential task of psychiatry" and in this we can only agree. It is sad that Dr Andrews fails to follow his own advice in his recent review. He has taken on the self-appointed role of 'Malleus maleficarum', the protector of a naive public from the evils of dynamic psychotherapy. As a result it would be quite possible for an observer to think that cognitive-behavioural therapists are immune from therapeutic error and that transference and countertransference can be totally expunged by keeping the therapy brief and focused.

It is subtly suggested that good clinical care is really an extension of good cognitive therapy. The work of Meares \& Hobson (1977) suggests, however, that the therapist is always at risk of becoming a persecutory figure to vulnerable patients. Their contribution, based firmly in the psychodynamic tradition, is now an accepted part of teaching doctors to be aware of interpersonal issues and the risks in any therapeutic approach. That such training is necessary for all psychiatrists, whether or not they eventually adopt a psychodynamic approach, is explicit in the guidelines for training of the Royal College of Psychiatrists.

Dr Andrews is right, however, to suggest that forming an alliance, understanding the "undercurrents', being professional and enthusiastic in addressing treatable symptoms, and persisting in providing care and support are all essential to good practice. Indeed, the thrust of much of the recent literature has favoured such an integrationist approach.

Eysenck (1952), in his classic analysis of psychotherapy versus natural remission, did a great service to psychotherapy researchers by prompting a thorough review of outcome assessment methodology, although it is now known that there were serious flaws in his own study. We hope that Dr Andrews' review could have as beneficial an effect in the 1990s as Eysenck had in the 1950 s. We are concerned, however, that Dr Andrews is generating a myth rather than a piece of reasoned appraisal.

His most extraordinary claim is that dynamic therapy is dangerous but cognitive-behavioural therapy is safe because "there are, as yet, no substantiated reports of harm" and because the treatment is short and so does not lead to transference and countertransference complications. We are surprised at such a disingenuous statement, and would point out that there is little to support his view that cognitive-behavioural therapy is intrinsically safer than other modes of therapy. All therapists need to be helped to identify areas of their practice which 
might be harmful or exploitative. The UK Council for the Psychotherapies requires all accredited member organisations to show how their training makes therapists aware of their own personal contributions to the process of therapy - this includes cognitivebehavioural therapists.

In a brief letter it is not possible to deal with all of the assertions about cost and efficacy. Briefly, we would suggest a different approach for purchasers of health care. We agree that there is good evidence that cognitive-behavioural therapy is effective and should be an integral part of any comprehensive service. It is striking, however, that direct comparisons between alternative modes of therapy usually reveal trivial treatment differences (the so called "equivalence paradox"; Stiles et al, 1986), even when studies are optimised to reveal such differences (e.g. Shapiro \& Firth, Journal, December 1987, 151, 790-799). In such a situation it is illogical to reduce patient choice. We would suggest that more sophisticated research is needed to examine the mechanisms underlying therapeutic change and the allocation of patients to specific types of therapy.

The arguments about cost are complex (McGrath \& Lowson, Journal, January 1986, 150, 65-71), but the work of Howard et al (1986) cited in the review does not support the conclusion reached by $\mathrm{Dr}$ Andrews. Howard and colleagues have pointed out that the gradient of the cost-benefit curve differs according to whether the target for improvement is distress, symptoms, or longer-term interpersonal dysfunction. Treatments of $\mathbf{5 0}$ sessions or more are then rational if the purchasers of health care are intending to provide more than just short-term, symptom-oriented treatment.

Dr Andrews' review deals specifically with the Australian health care system and it is important to note that in the UK the proportion of patients receiving long-term psychotherapy (more than 50 sessions) is small, even in specialist psychotherapy departments.

We would agree with Dr Andrews that it is necessary to be discriminating in the selection of patients and in attempting to minimise harmful effects, but his polemical view that dynamic therapies have no role in public sector services goes considerably beyond the evidence available and should not go unchallenged.

EYSENCK, H. J. (1952) The effect of psychotherapy: an evaluation. Journal of Consulting Psychology, 16, 319-324.

Howard, K. I., Kopta, S. M., Krause, M. S., et al (1986) The doseeffect relationship in psychotherapy. American Psychologist, 41, 159-164.

MeAres, R. \& Hobson, R. F. (1977) The persecutory therapist. British Journal of Medical Psychology, 50, 349-359.
Stiles, W. B., Shapiro, D. A. \& Elliott, R. (1986) Are all psychotherapies equivalent? American Psychologist, 41, 165-180.

F. MARGiSON G. MCGRATH

Department of Psychiatry

Manchester Royal Infirmary

Oxford Road

Manchester M13 9BX

\section{Integration of psychodynamics in Scandinavian psychiatry}

SIR: The recent death of Erik Strömgren in Aarhus, Denmark, marks the passing of a remarkable man who was largely responsible for the international reputation long enjoyed by the Risskov Hospital. His breadth of vision was similar to that of Aubrey Lewis, who built up the Maudsley Hospital. When Denis Hill was appointed successor to Lewis, he was particularly concerned to teach that the psychiatrist should be literate in both psychodynamic and biological discourse (Hill, Journal, August 1978, 133, 97-105). These leaders insisted that all aspects of psychiatry should be adequately represented under one roof of a great teaching centre, an attitude which encouraged the pursuit of an integrated psychiatry in which neuroscience and psychodynamics are fully integrated.

Strömgren's legacy can be seen today in the Risskov Hospital, where Mogens Schou, the doyen of lithium researchers, is still working, although retired, in the same hospital in which epidemiological research is active, and psychoanalytic ideas and psychotherapy are flourishing. The large and active psychotherapy department provides training for nurses in the elements of psychodynamics and the integration of the psychotherapeutic perspective into the treatment plans for psychotic patients. Many senior consultants are themselves practising individual psychotherapy with selected psychotic patients and supervising trainees, with encouraging results.

In many Scandinavian countries such an integrated approach has been the rule for decades. A group of practitioners, eminent in their field, have recently formed the Nordic Association for the Psychotherapy of Psychosis, for the purpose of exchanging experiences and research across the borders of the Scandinavian countries. They have just published a book of essays by founder members. This small book, Crossing the Borders (Hansen, 1993), contains several papers that should be of great interest to British psychiatrists. Perhaps the most compelling is the description of the Finnish 'needadapted' approach to the treatment of schizophrenic psychoses. 